\title{
Improvement of Lifetime Using Transition Metal-Incorporated SAPO-34 Catalysts in Conversion of Dimethyl Ether to Light Olefins
}

\author{
Hyo-Sub Kim, ${ }^{1}$ Su-Gyung Lee, ${ }^{1}$ Young-Ho Kim, ${ }^{1}$ Dong-Hee Lee, ${ }^{1}$ \\ Jin-Bae Lee, ${ }^{2}$ and Chu-Sik Park ${ }^{3}$ \\ ${ }^{1}$ Department of Fine Chemical Engineering and Applied Chemistry, Chungnam National University, \\ 220 Gung-dong, Yuseong-gu, Daejeon 305-764, Republic of Korea \\ ${ }^{2}$ Division of Materials Science, Korea Basic Science Institute, 52 Eoeun-dong, Yuseong-gu, Daejeon 305-333, Republic of Korea \\ ${ }^{3}$ Hydrogen Energy Research Group, Korea Institute of Energy Research, 71-2 Jang-dong, Yuseong-gu, \\ Daejeon 305-343, Republic of Korea
}

Correspondence should be addressed to Young-Ho Kim; yh_kim@cnu.ac.kr

Received 13 August 2013; Accepted 10 September 2013

Academic Editor: Yun Suk Huh

Copyright (C) 2013 Hyo-Sub Kim et al. This is an open access article distributed under the Creative Commons Attribution License, which permits unrestricted use, distribution, and reproduction in any medium, provided the original work is properly cited.

Transition metal (Mn, Fe, or Ni) incorporated SAPO-34 (MeAPSO-34) nanocatalysts were synthesized using a hydrothermal method to improve the catalytic lifetime in the conversion of dimethyl ether to light olefins (DTO). The structures of the synthesized catalysts were characterized using several methods including XRD, SEM, BET, ${ }^{29}$ Si-MAS NMR, and $\mathrm{NH}_{3}-\mathrm{TPD}_{\text {techniques. }}$ Although the structure of the MeAPSO-34 catalysts was similar to that of the SAPO-34 catalyst, the amount of weak acid sites in all MeAPSO-34 catalysts was markedly increased and accompanied by differences in crystallinity and structural arrangement. The amount of weak acid sites decreased in the following order: NiAPSO-34 > FeAPSO-34 > MnAPSO-34 > SAPO-34 catalyst. The MeAPSO-34 catalysts, when used in the DTO reaction, maintained DME conversion above $90 \%$ for a longer time than the SAPO34 catalyst, while also maintaining the total selectivity above $95 \%$ for light olefins. In addition, the NiAPSO-34 catalyst showed the longest catalytic lifetime; the lifetime was extended approximately 2-fold relative to the SAPO-34 catalyst. Therefore, the increase in the catalytic lifetime is related to the amount of weak acidic sites, and these sites are increased in number by incorporating transition metals into the SAPO-34 catalyst.

\section{Introduction}

As a microporous material, aluminophosphates (AlPO) nanomolecular sieves have been used in many processes as a shape-selective catalyst [1-5]. The structure of AlPO molecular sieves is mainly composed of Al-O-P linkages and is very similar to that of zeolite. However, AlPO molecular sieves are electrically neutral due to their structure, in addition to completely lacking acidic sites and catalytic properties. It leads to the formation of the silicoaluminophosphate (SAPO) molecular sieves by introducing $\mathrm{Si}$ atoms into the AlPO framework [6-8]. The substitution of Si atoms for the phosphorus in the AlPO generated an electrically negative character because the Si required extra lattice cations. Consequently, the SAPO molecular sieves have Brønsted acidic sites and are active in acid-catalyzed reactions.

The DTO process is an important technique used to produce light olefins starting from alternative energy sources, such as coal, natural gas, and biomass. Among the SAPO molecular sieves, the SAPO-34 catalyst has high selectivity for light olefins production due to its shape selectivity during the methanol to light olefins (MTO) and DTO reactions; numerous studies have been conducted to improve the lifetime of this catalyst [9-22]. To enhance the catalytic lifetime, various transition metals are incorporated into the SAPO-34 framework via isomorphous substitution to form MeAPSO-34 molecular sieves [23-28]. Studies using MeAPSO-34 molecular sieves have been focused on the variation of framework 
arrangement and therefore the acidic sites by incorporating transition metals. The framework of the SAPO molecular sieves is a tetrahedral structure comprised of $\mathrm{Al}, \mathrm{P}$, and $\mathrm{Si}$ atoms. The transition metals form $\mathrm{P}(n \mathrm{Al},(4-n) \mathrm{Me})$ chemical environments by substituting the $\mathrm{Al}^{3+}$ sites in this framework. The incorporation of transition metals influences the arrangement of the $\mathrm{Si}$ atoms, which can only be substituted at the $\mathrm{P}(4 \mathrm{Al})$ sites [29]. It induces a difference in acidity and catalytic activity compared with SAPO-34 because the Si atom plays an important role during acidic site formation in SAPO-34. In many studies of the MeAPSO-34 catalysts, the variation of the synthetics conditions, starting material and reaction conditions provided different results. Dubois et al. [30] reported that a MnAPSO-34 catalyst exhibited improved catalytic activity compared with SAPO-34, while NiAPSO-34 and CoAPSO-34 catalysts demonstrated low catalytic activity during MTO process. Salmasi et al. [31] reported that a NiAPSO-34 catalyst prepared by combining TEAOH and morpholine as structure directing agents (SDA) showed the highest activity in the MTO process. In addition, the MeAPSO-34 catalysts synthesized by incorporating Fe, Co, and $\mathrm{Mn}$ exhibited enhanced catalytic lifetimes and properties in comparison with SAPO-34 when transforming chloromethane into light olefins [32]. However, while the performance of all MeAPSO-34 catalysts has been tested in the MTO reaction, not all catalysts of this type have been tested in the DTO reaction. The amount of water formed during the DTO reaction is much lower than that formed during the MTO reaction because DTO reaction does not require the dehydration step needed to turn methanol into dimethyl ether. The water formation may affect the coke formation, which is a primary cause of catalyst deactivation. Therefore, the performance of the MeAPSO-34 catalyst must be confirmed in a reaction using dimethyl ether as a raw material.

In this work, the MeAPSO-34 catalysts by incorporating various metals $(\mathrm{Mn}, \mathrm{Fe}$, or $\mathrm{Ni}$ ) were prepared using a hydrothermal method. Physicochemical properties of the prepared catalysts were studied using SEM, XRD, and BET. The variations in the structure and acidity of molecular sieves were characterized using ${ }^{29} \mathrm{Si}$ magic-angle spinning (MAS) NMR and ammonia temperature-programmed desorption $\left(\mathrm{NH}_{3}-\mathrm{TPD}\right)$. At this point, we have focused on the acidic site of catalyst that influences the efficiency of DTO process. DTO reactions were conducted using the MeAPSO-34 catalysts to evaluate the catalytic performance and lifetime, as well as the selectivity for light olefins.

\section{Experimental}

2.1. Catalyst Preparation. The SAPO-34 and MeAPSO-34 $(\mathrm{Me}=\mathrm{Mn}, \mathrm{Fe}$, or $\mathrm{Ni})$ catalysts were prepared based on a procedure in the literature [33]. The gel composition was $1.0 \quad \mathrm{Al}_{2} \mathrm{O}_{3}: 1.0 \quad \mathrm{P}_{2} \mathrm{O}_{5}: 0.3 \quad \mathrm{SiO}_{2}: 1.0$ TEAOH:1.0 DEA $: 52$ $\mathrm{H}_{2} \mathrm{O}$ (mol). The molar compositions of the MeAPSO-34 catalysts were $0.005 \mathrm{Me}: 1.0 \mathrm{Al}_{2} \mathrm{O}_{3}: 1.0 \mathrm{P}_{2} \mathrm{O}_{5}: 0.3 \mathrm{SiO}_{2}: 1.0$ TEAOH:1.0 DEA:52 $\mathrm{H}_{2} \mathrm{O}$ (mol). The starting materials for the alumina, phosphorous, and silica were aluminium isopropoxide (Junsei, 99\%), phosphoric acid (Samchun chemicals, 85\%), and LUDOX AS-40 (Sigma-Aldrich, 40\%),

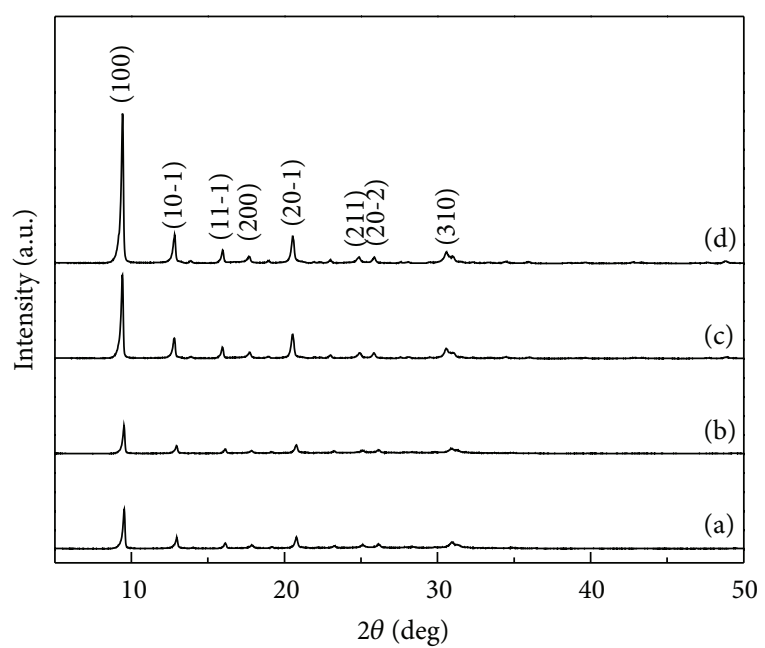

FIGURE 1: XRD patterns of the SAPO-34 and MeAPSO-34 catalysts: (a) SAPO-34, (b) MnAPSO-34, (c) FeAPSO-34, and (d) NiAPSO34 .

respectively. Tetraethylammonium hydroxide (TEAOH, Samchun chemicals, 25\%) and diethylamine (DEA, Junsei, 99\%) were used as structure directing agents. Nickel (II) nitrate $\left(\mathrm{Ni}\left(\mathrm{NO}_{3}\right)_{2} \cdot 6 \mathrm{H}_{2} \mathrm{O}, \mathrm{DC}\right.$ chemical, 98.5\%), iron (III) nitrate $\left(\mathrm{Fe}\left(\mathrm{NO}_{3}\right)_{3} \cdot 9 \mathrm{H}_{2} \mathrm{O}\right.$, Kanto chemical, 99.0\%), and manganese (II) nitrate $\left(\mathrm{Mn}\left(\mathrm{NO}_{3}\right)_{2} \cdot 6 \mathrm{H}_{2} \mathrm{O}\right.$, Kanto chemical, $98.0 \%)$ were utilized as the transition metal sources.

The catalysts were prepared using a hydrothermal synthesis process in an autoclave. DEA and deionized water were added to aluminum isopropoxide, and phosphoric acid was subsequently added dropwise over $2 \mathrm{~h}$ with stirring. A solution of LUDOX AS-40 and TEAOH was added to the mixture over a period of $1 \mathrm{~h}$. For the MeAPSO-34 catalysts, a metal salt was added to the mixture with stirring for $1 \mathrm{~h}$. The final gel was transferred into an autoclave and heated at $200^{\circ} \mathrm{C}$ for $72 \mathrm{~h}$. After crystallization, the prepared samples were filtered, washed, dried at $100^{\circ} \mathrm{C}$ and calcined at $600^{\circ} \mathrm{C}$ for $6 \mathrm{~h}$ to obtain the final catalyst. The obtained samples were designated MnAPSO-34, FeAPSO-34 and NiAPSO-34 for $\mathrm{Mn}, \mathrm{Fe}$ and $\mathrm{Ni}$, respectively.

2.2. Characterization. The crystallinity and composition of the catalysts were characterized using X-ray diffraction (XRD, Rigaku D/max III-B) with $\mathrm{Cu} \mathrm{K} \alpha$ radiation. The XRD measurements were recorded in the angle range of $5^{\circ}<2 \theta<$ $50^{\circ}$ at $40 \mathrm{kV}$ and $30 \mathrm{~mA}$. The particle size and morphology of the catalysts were observed by scanning electron microscopy (SEM, Hitachi, S-4800). The Brunner-Emmett-Teller (BET) surface areas of the prepared catalysts were measured at $77 \mathrm{~K}$ using the isotherm data from the nitrogen adsorptiondesorption obtained using a Micromeritics ASAP-2400 analyzer.

${ }^{29}$ Si MAS NMR spectra were recorded with a Varian 500 and a Bruker solid-state NMR spectrometer. The Larmor frequency was $79.488 \mathrm{MHz}$. The acidity of the catalyst was measured using $\mathrm{NH}_{3}$-TPD. Before analysis, approximately $0.2 \mathrm{~g}$ of the prepared catalyst was activated at $600^{\circ} \mathrm{C}$ for $2 \mathrm{~h}$ in 


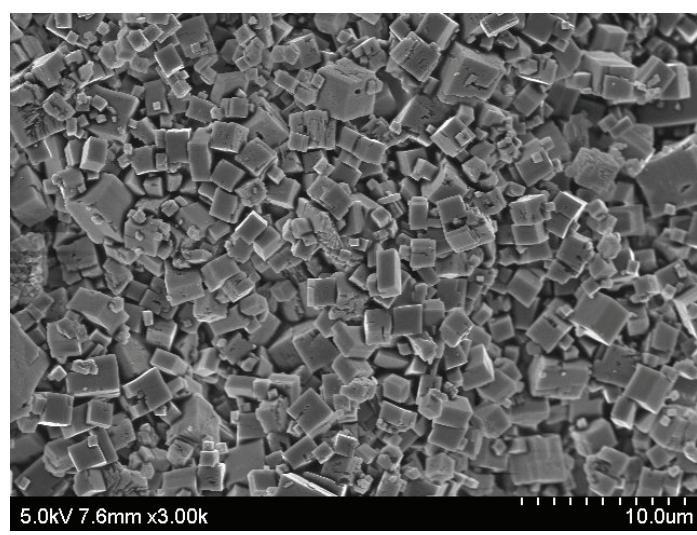

(a)

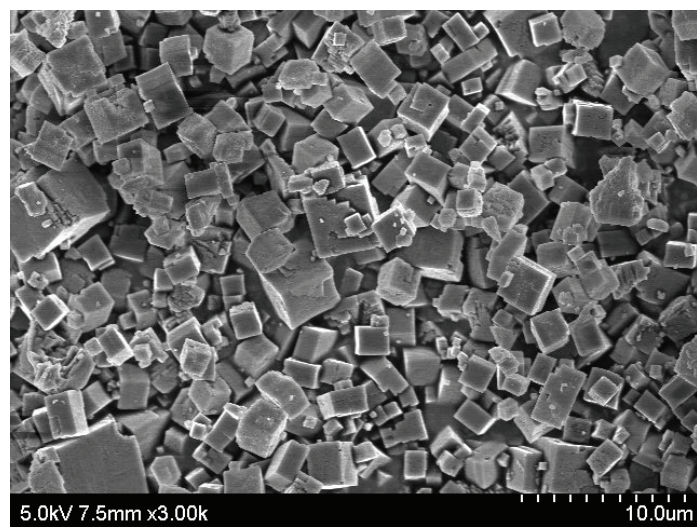

(c)

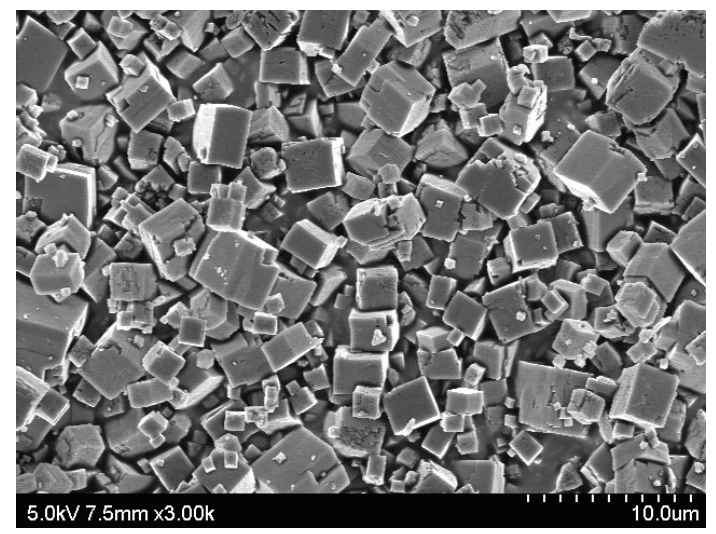

(b)

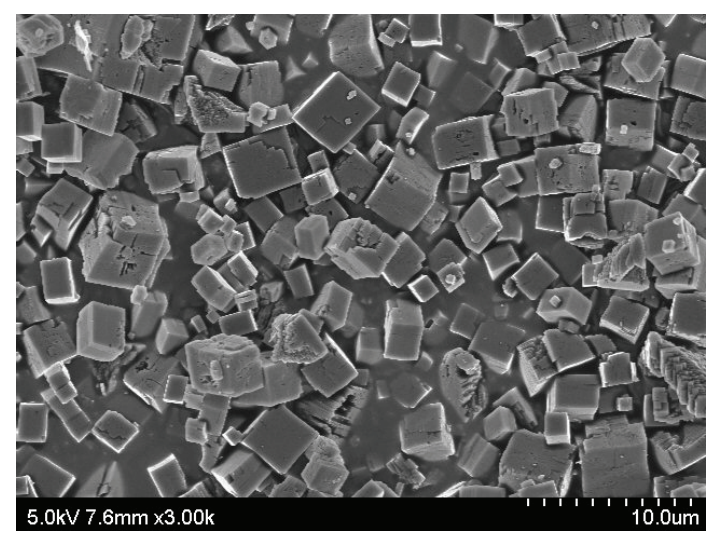

(d)

FIgUre 2: SEM images of the SAPO-34 and MeAPSO-34 catalysts: (a) SAPO-34, (b) MnAPSO-34, (c) FeAPSO-34, and (d) NiAPSO-34.

helium flowing at $30 \mathrm{~mL} / \mathrm{min} . \mathrm{NH}_{3}$ gas was injected at $100^{\circ} \mathrm{C}$ to saturate the catalysts for $1 \mathrm{~h}$. After adsorbing the $\mathrm{NH}_{3}$, the catalysts were kept under flowing helium until the TCD signal indicating the $\mathrm{NH}_{3}$ was absent. Afterward, the $\mathrm{NH}_{3}$-TPD was operated within $100-700^{\circ} \mathrm{C}$ under a helium flow at $30 \mathrm{~mL} / \mathrm{min}$.

2.3. DTO Reaction. The DTO reaction was conducted in a fixed bed reactor under atmospheric pressure. The catalyst $(0.2 \mathrm{~g})$ was charged into the center of the quartz reactor $($ O.D. $=1.1 \mathrm{~cm})$, and the reaction temperature was measured with the thermocouple inside the catalyst bed. Before the reaction, a pretreatment proceeded for $1 \mathrm{~h}$ under flowing $\mathrm{N}_{2}$ at atmospheric pressure at $400^{\circ} \mathrm{C}$. After the pretreatment, the DME and $\mathrm{N}_{2}$ were introduced into the reactor at the desired flow rate using a mass flow controller (MFC). The volume ratio of the DME and $\mathrm{N}_{2}$ mixed gas was fixed at 1:3. The weight hourly space velocity (WHSV) of DME was $3.54 \mathrm{~h}^{-1}$. The DTO reaction products were analyzed online with a gas chromatograph (GC, HP 5890 plus) equipped with a capillary column (HP-plot Q, L $30 \mathrm{~m} \times$ I.D. $0.320 \mathrm{~mm}$ ) and a flame ionization detector (FID).

\section{Results and Discussion}

3.1. Catalyst Characterization. Figure 1 shows the XRD patterns of the prepared SAPO-34 and MeAPSO-34 catalysts. We observed the chabazite structure of catalyst based on the main peaks at $9.5^{\circ}, 20.8^{\circ}$, and $12.9^{\circ}$ in the XRD patterns [34]. The peak intensities of the $\mathrm{Fe}$ - and $\mathrm{Ni}$-incorporated catalysts are much higher than that of the SAPO-34 catalyst. This finding indicates that the quantity of particle formed as crystal in the MeAPSO-34 catalysts is relatively large. There are also no additional peaks. The SEM images of the SAPO-34 and MeAPSO-34 catalysts are shown in Figure 2. The crystals of the SAPO-34 catalyst exhibit a cubic morphology with 2-5 $\mu \mathrm{m}$ crystals (Figure 2(a)). The crystal size of MeAPSO34 catalysts is slightly higher than that of the SAPO-34 catalyst, while a similar cubic morphology was observed for the MeAPSO-34 catalysts. Therefore, the incorporation of transition metal ions into the SAPO-34 framework barely affected the cubic morphology. The small changes in the crystal sizes may be attributed to the differences in the sizes of the metal ions substituted with $\mathrm{Al}$ ion in the SAPO-34 framework [27]. Table 1 shows the textural properties of the SAPO-34 and MeAPSO-34 catalysts. The surface area was calculated over the relatively pressure ranges $p / p_{0}$ from 0.05 to 0.30 . The surface areas of the SAPO-34, MnAPSO-34, FeAPSO-34, and NiAPSO-34 catalysts were approximately $539,543,533$, and $564 \mathrm{~m}^{2} / \mathrm{g}$, respectively. All of the MeAPSO-34 catalysts revealed similar total pore volumes $\left(0.25 \mathrm{~cm}^{3} / \mathrm{g}\right)$ and adsorption average pore widths $(2.46 \mathrm{~nm})$. Therefore, the physical and porous structures of the MeAPSO-34 catalysts are very 


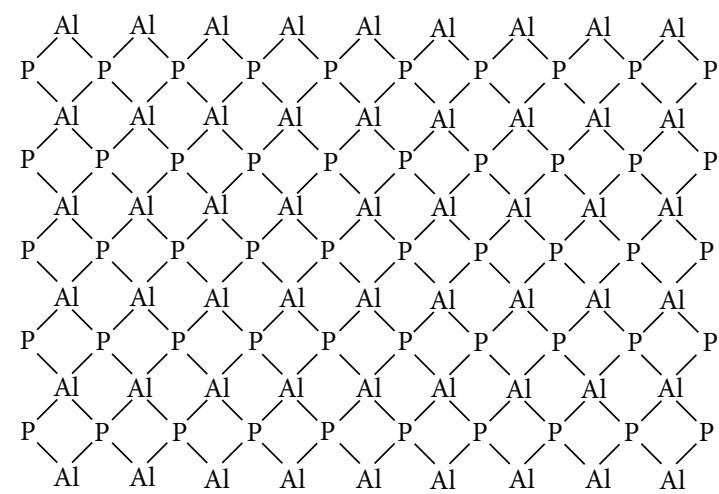

(a)

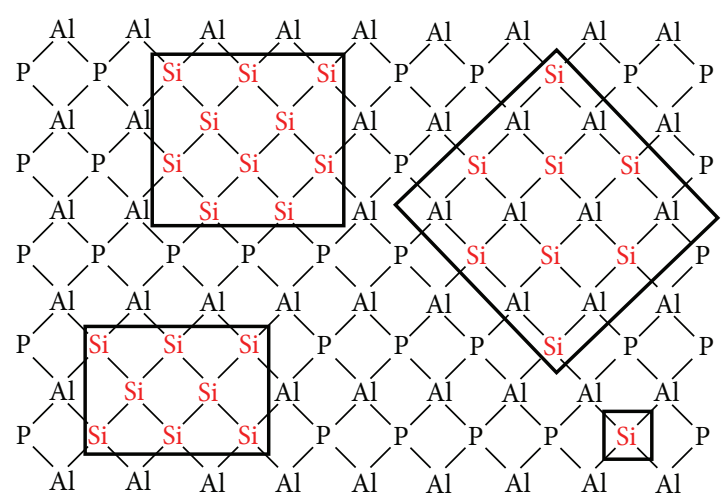

(b)

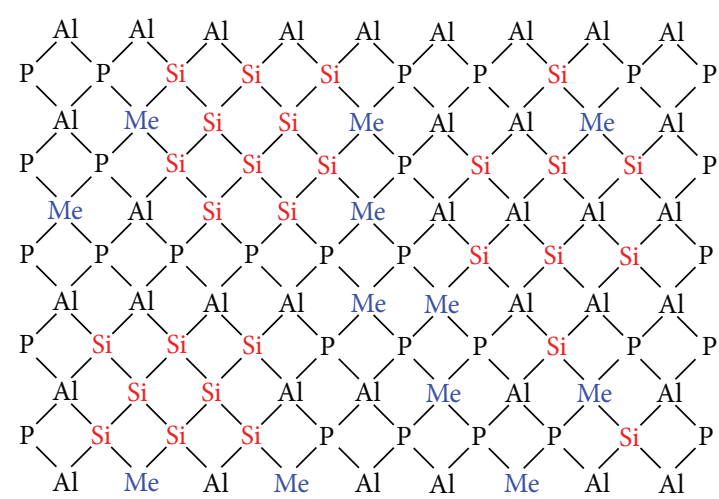

(c)

FIgURE 3: Scheme demonstrating the possible ways to introduce Si into the AlPO framework and a transition metal into the SAPO framework (oxygen atoms are not represented for clarity): (a) AlPO, (b) SAPO, and (c) MeAPSO.

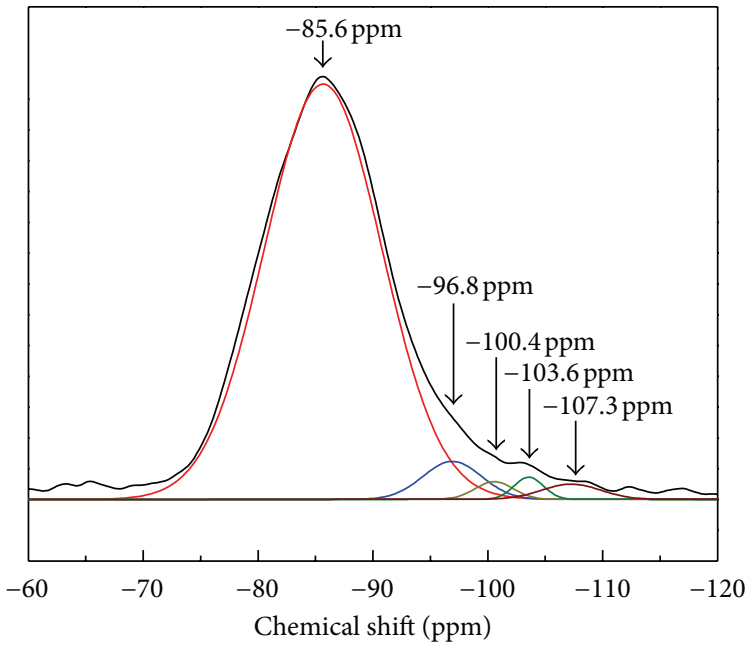

(a)

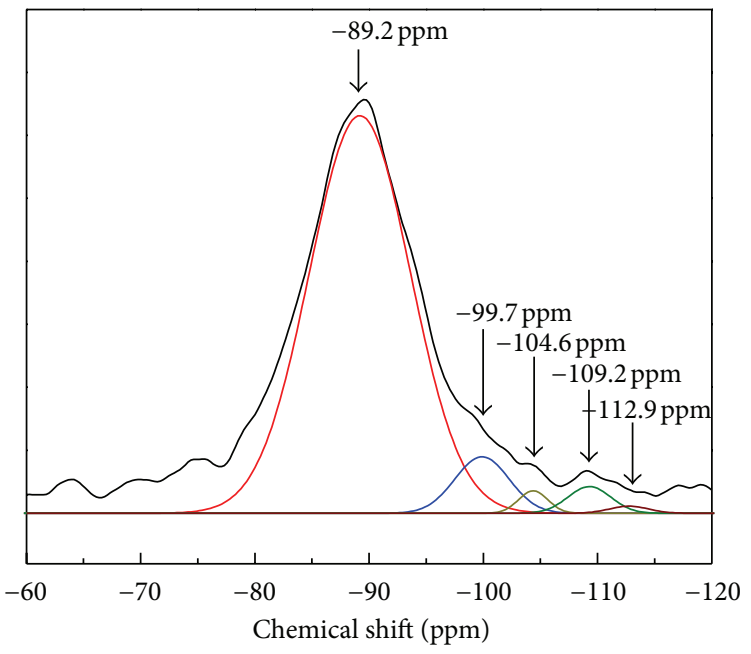

(b)

Figure $4:{ }^{29}$ Si MAS NMR spectra of the (a) SAPO-34 and (b) NiAPSO-34 catalysts.

similar, which is consistent with XRD and SEM data. The results described above also demonstrate that the MeAPSO34 catalysts are similar to the SAPO-34 catalyst in their morphologies and porous and crystalline structures, although their crystal sizes were found to be somewhat larger.
The variation in the framework starting from the AlPO molecular sieves and leading to MeAPSO-34 catalyst is illustrated in Figure 3 (i.e., AlPO $\rightarrow$ SAPO $\rightarrow$ MeAPSO). The SAPO material with acidic sites was formed by substituting the $\mathrm{P}$ ions with $\mathrm{Si}$ ions in the framework of an AlPO 
TABLE 1: Textural properties of the SAPO-34 and MeAPSO-34 catalysts.

\begin{tabular}{lccc}
\hline Catalyst & $\begin{array}{c}\text { BET surface } \\
\text { area }\left(\mathrm{m}^{2} / \mathrm{g}\right)\end{array}$ & $\begin{array}{c}\text { Total pore } \\
\text { volume }\left(\mathrm{cm}^{3} / \mathrm{g}\right)\end{array}$ & $\begin{array}{c}\text { Adsorption average } \\
\text { pore width }(\mathrm{nm})\end{array}$ \\
\hline SAPO-34 & 538.79 & 0.39 & 2.92 \\
MnAPSO-34 & 543.30 & 0.25 & 2.42 \\
FeAPSO-34 & 533.27 & 0.26 & 2.62 \\
NiAPSO-34 & 564.31 & 0.26 & 2.34 \\
\hline
\end{tabular}

TABLE 2: Measured acidity during the ammonia temperatureprogrammed ammonia desorption.

\begin{tabular}{lccc}
\hline Catalyst & \multicolumn{4}{c}{$\begin{array}{c}\text { Acidity: } \mathrm{NH}_{3} \text { desorption amounts }(\mathrm{mmol} / \mathrm{g}) \\
\text { Weak }\end{array}$} & $\begin{array}{c}\text { Strong } \\
290-310^{\circ} \mathrm{C}\end{array}$ & $460-500^{\circ} \mathrm{C}$ & Total amount \\
\hline SAPO-34 & 0.3426 & 0.4466 & 0.7891 \\
MnAPSO-34 & 0.3795 & 0.5013 & 0.8809 \\
FeAPSO-34 & 0.4460 & 0.5100 & 0.9560 \\
NiAPSO-34 & 0.5638 & 0.4959 & 1.0598 \\
\hline
\end{tabular}

material, which has no acidity (see Figures 3(a) and 3(b)). The transition metal ions added to a SAPO material may be incorporated by substituting for the $\mathrm{Al}$ ions in the framework of the material, as illustrated in Figure 3(c). Consequently, the amount of acidic sites would be changed by incorporating transition metals, affecting the catalytic activity.

The ${ }^{29}$ Si MAS NMR data for the SAPO-34 and NiAPSO34 catalysts are shown in Figure 4. The SAPO-34 catalyst shows the five resonance signals with chemical shifts at $-85.6,-96.8,-100.4,-103.6$, and $-107.3 \mathrm{ppm}$, indicating the coordination states attributed to $\mathrm{Si}(4 \mathrm{Al}), \mathrm{Si}(3 \mathrm{Al}), \mathrm{Si}(2 \mathrm{Al})$, $\mathrm{Si}(1 \mathrm{Al})$, and $\mathrm{Si}(0 \mathrm{Al})$, respectively $[35,36]$. For the NiAPSO34 catalyst, no additional peaks appeared in the ${ }^{29} \mathrm{Si}$ MAS NMR spectrum, indicating that the Si-O-Ni bond did not form because the substitutions of $\mathrm{Si}$ atoms for $\mathrm{P}$ atoms that are linked to one or more $\mathrm{Ni}$ atoms are difficult. However, the peak positions were slightly shifted in comparison with the SAPO-34 catalyst, resulting in the peaks being observed at $-89.2,-99.7,-104.6,-109.2$, and $-112.9 \mathrm{ppm}$. Therefore, the MeAPSO-34 catalyst's framework had changed relative to the SAPO-34 catalyst. The intensity of NiAPSO-34 catalyst is slightly higher than that of SAPO-34 catalyst, indicating that more Si islands are present in the SAPO framework due to incorporation of transition metals.

The acidity and strength of acid sites on the SAPO34 and MeAPSO-34 catalysts are shown in Figure 5 and Table 2. As shown in Figure 5, two representative peaks were observed for the catalysts, and the peaks at low (290$\left.310^{\circ} \mathrm{C}\right)$ and high temperatures $\left(460-500^{\circ} \mathrm{C}\right)$ were attributed to the strong and weak acidic sites, respectively. The acidity of the MeAPSO-34 catalysts was relatively higher than that of the SAPO-34 catalyst. In particular, the variation in weak acidic sites of MeAPSO-34 catalysts significantly increased than the variation in strong acidic sites. Therefore, the acidity changes in catalysts are caused by the variations in crystallinity or structural arrangement of the

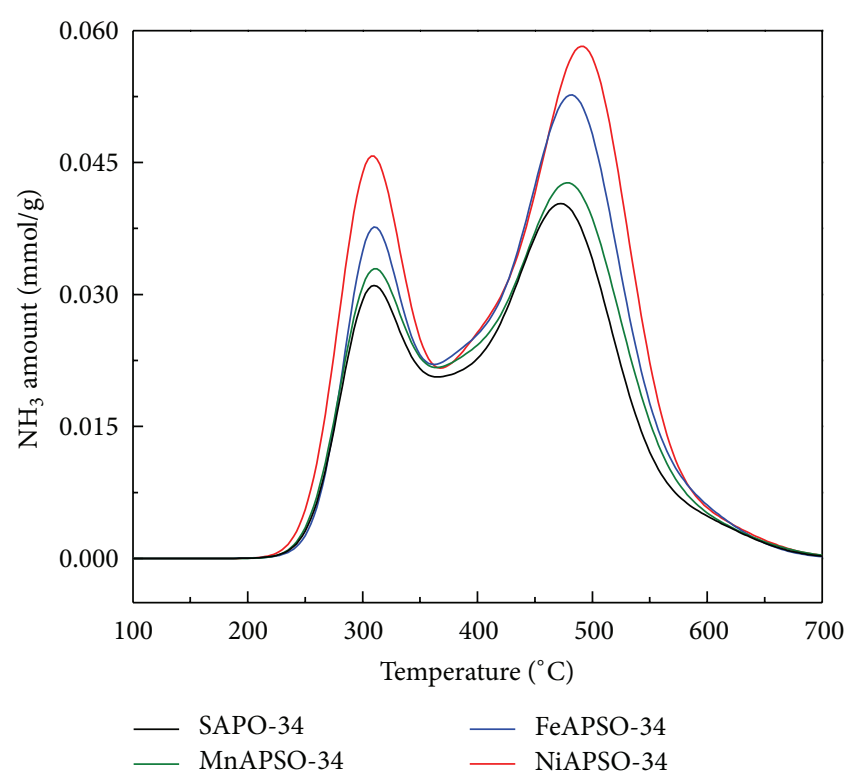

FIGURE 5: $\mathrm{NH}_{3}$-TPD profiles of the SAPO-34 and MeAPSO-34 catalysts.

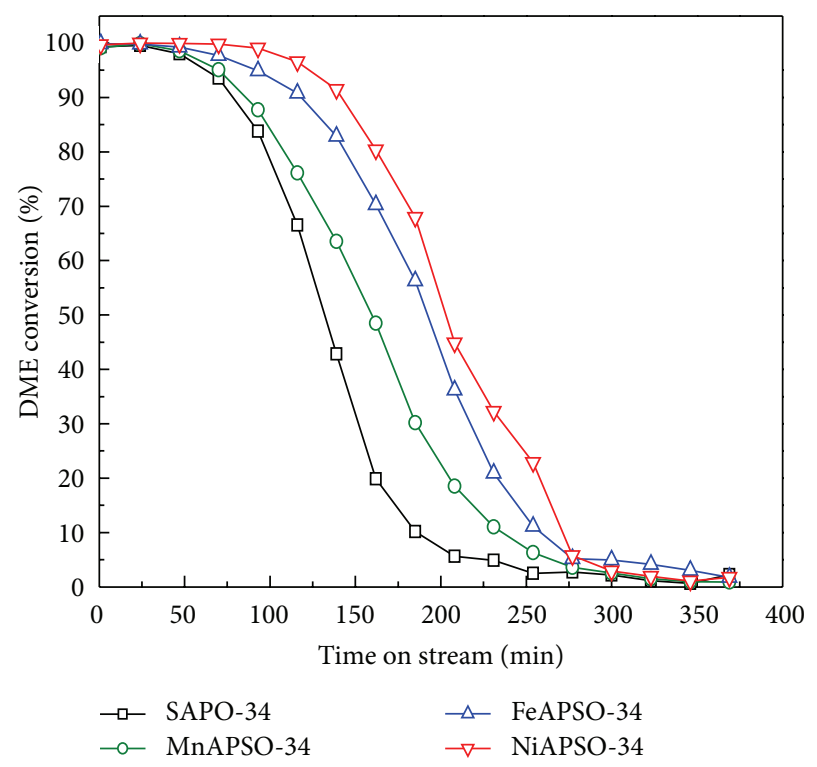

Figure 6: DME conversion over the SAPO-34 and MeAPSO-34 catalysts.

catalysts observed by ${ }^{29} \mathrm{Si}$ MAS NMR. The incorporated metal replaces the $\mathrm{Al}$ atoms in the catalyst framework, modulating the acidity $[27,28]$. Among the MeAPSO-34 catalysts, the NiAPSO-34 catalyst demonstrates the highest acidity and the acidity decreased in the following order: NiAPSO-34 > FeAPSO-34 > MnAPSO-34.

3.2. Catalytic Performance in DTO Reaction. The DTO reaction performed over the MeAPSO-34 catalysts to identify the catalytic performances. For all of the catalysts, $100 \%$ conversion of DME was obtained during the initial stages of 


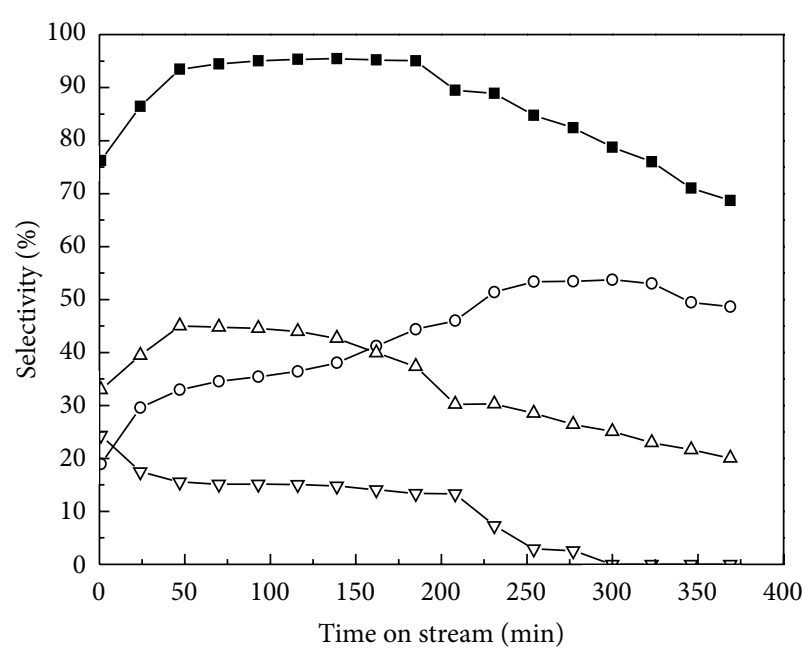

(a)

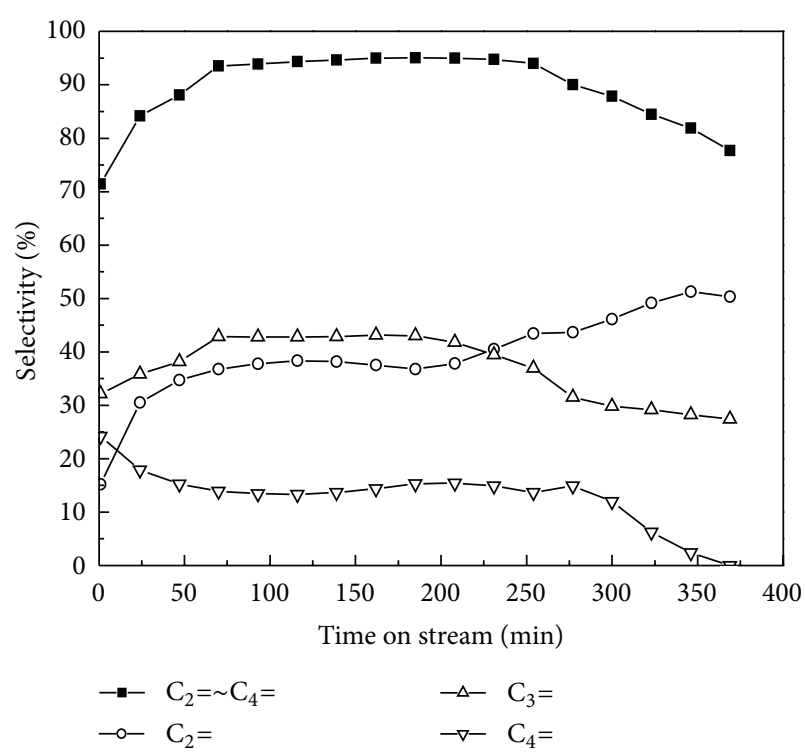

(c)

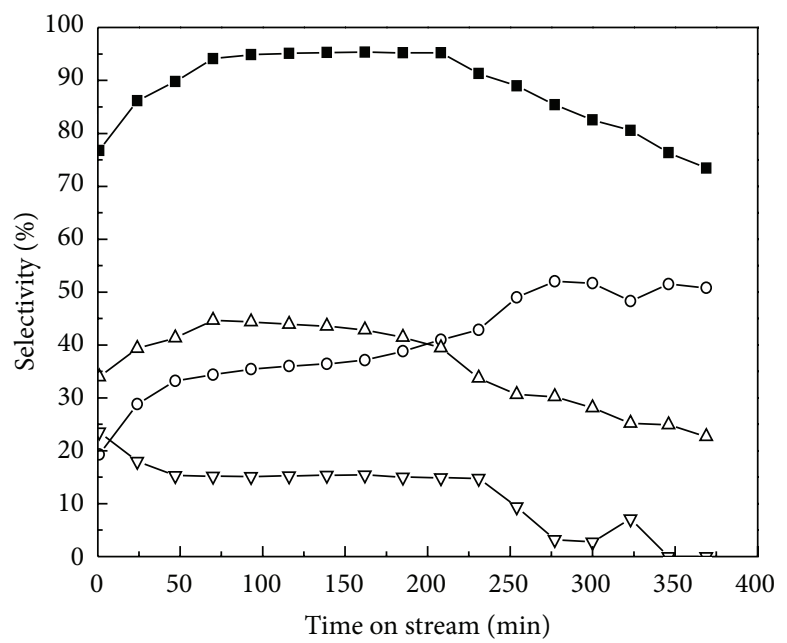

(b)

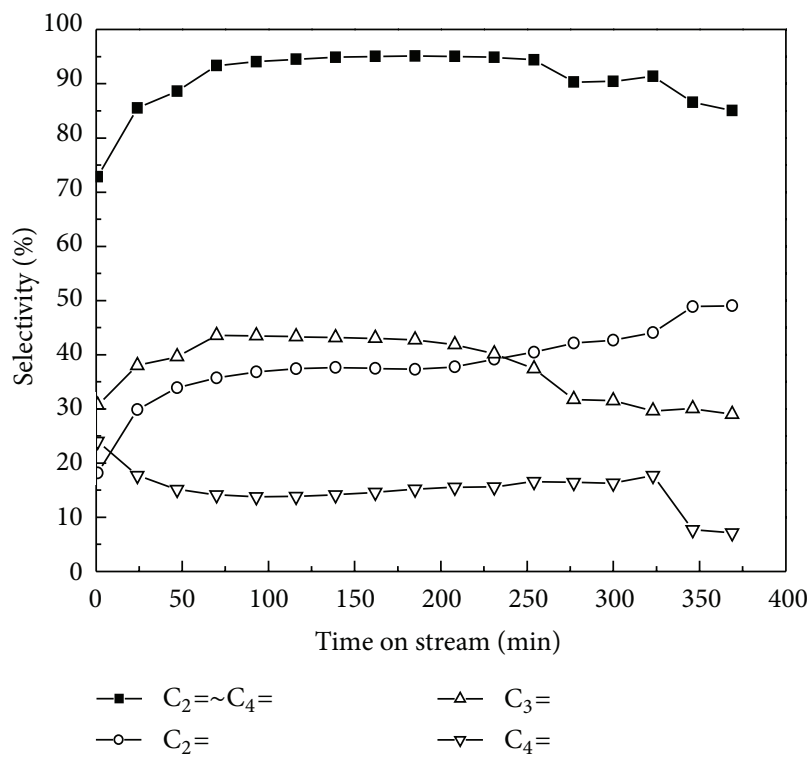

(d)

FIGURE 7: Selectivity for light olefins over the SAPO-34 and MeAPSO-34 catalysts: (a) SAPO-34, (b) MnAPSO-34, (c) FeAPSO-34, and (d) NiAPSO-34.

the reaction, and the DME conversion decreased during the reaction as shown in Figure 6. This tendency is attributed to the conversion of intermediates formed in the catalytic pores [12]. Methylbenzene, such as hexamethylbenzene (HMB), generated in the cages of the catalysts and these compounds assist the DTO reaction. As the reaction time increases, the methylbenzene gradually changes to polyaromatic hydrocarbons (PAH) via additional condensation and cyclization reactions at the same time $[13,37]$. The DTO reaction cannot continue in the PAH-filled cages due to the transport limitation of the reactants and products. Consequently, the DME conversion decreased for all the catalysts during the reaction. The high DME conversion observed for the MeAPSO-34 catalysts was maintained over a relatively long time compared to the SAPO-34 catalyst because the acidic sites varied in strength due to the metal incorporation. The catalytic activity increased as the amount of acidic sites increased. In addition, the DTO reaction occurred under mild conditions, and the high DME conversion was maintained for long periods due to the increased amount of weak acidic sites.

Figures 7 and 8 show the selectivities for the light olefins and hydrocarbons. For the SAPO-34 catalyst, the total selectivity toward light olefins was approximately $79.2 \%$ at the beginning of the reaction, remaining approximately $94.8 \%$ at the duration from $47 \mathrm{~min}$ to $185 \mathrm{~min}$ and finally decreasing to approximately $68.7 \%$ after further time on the stream. Unlike the selectivity toward light olefins, the selectivity for hydrocarbons decreased approximately from $23.8 \%$ to $4.9 \%$ at the initial reaction time; this value was maintained up to $185 \mathrm{~min}$, but increased afterward to approximately $31.3 \%$. The selectivity toward propylene increased approximately $32.9 \%$ to $45.0 \%$ at the beginning of the reaction; this value significantly 


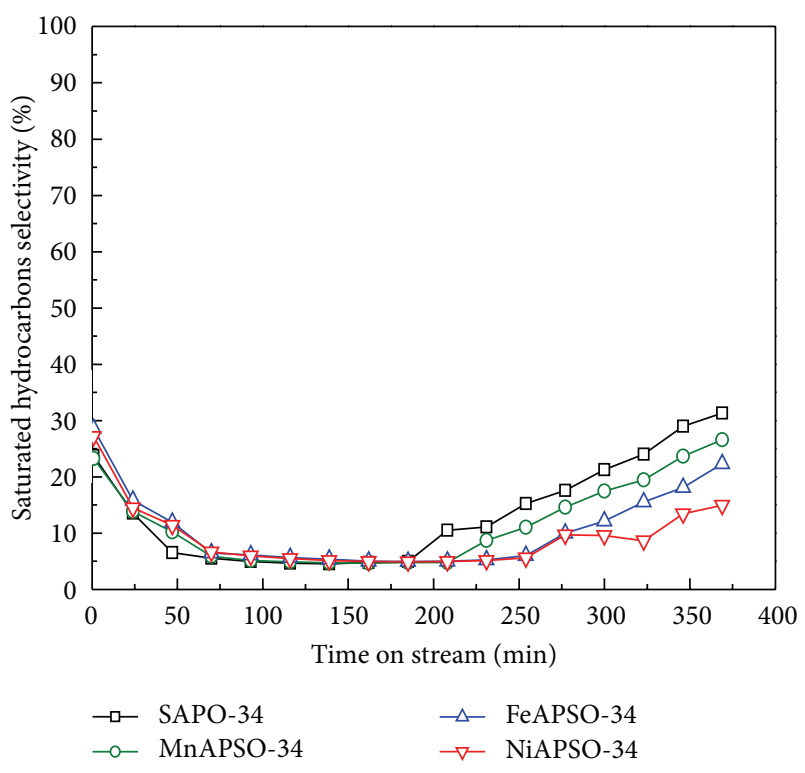

FIGURE 8: Selectivity for saturated hydrocarbons over the SAPO-34 and MeAPSO-34 catalysts.

decreased after $185 \mathrm{~min}$. The selectivity for ethylene gradually increased to approximately $48.6 \%$. The difference in selectivities for the light olefins and hydrocarbons is attributed to the same reasons for the decrease in DME conversion (coke deposition). Catalyst deactivation occurs because the coke deposits cover the active sites as the time on the stream increases. Therefore, the selectivity for the light olefins decreased, while that for the hydrocarbons increased as the time on stream increased. In addition, the differences in selectivity for ethylene, propylene, and butylene are attributed to a hydrocarbon pool mechanism [38]. Aromatic compounds, such as methylbenzene or hexamethylbenzene, were formed within a catalytic cage, and the ethyl groups were formed and eliminated simultaneously due to the space constraints of cage. Therefore, the selectivity for ethylene differs from that for propylene and butylenes. This result is consistent with previous work [22] that investigated the characteristics of the SAPO-34 catalyst during DTO reactions. Although the selectivity for light olefins and hydrocarbons over the MeAPSO34 catalysts was similar to that of the SAPO-34 catalyst, the time needed to keep the total selectivity above 95\% for light olefins over the MeAPSO-34 catalysts is higher than that for the SAPO-34 catalyst. Specifically, the times needed to maintain the high selectivity of MnAPSO-34, FeAPSO-34, and NiAPSO-34 catalysts for light olefins were 208, 254, and $254 \mathrm{~min}$, respectively. The catalytic lifetime is defined as the time during the reaction until DME conversion drops below $90 \%$. The lifetimes of the SAPO-34 and MeAPSO-34 catalysts are shown in Figure 9. The catalytic lifetime of the MeAPSO34 catalysts was longer than that of the SAPO-34 catalyst, and the catalytic lifetimes of the SAPO-34, NiAPSO-34, FeAPSO34, and MnAPSO-34 catalysts are 79, 86, 118, and $142 \mathrm{~min}$, respectively.

From the results of DTO reaction, it was observed that the MeAPSO-34 catalysts show long catalytic lifetimes and high

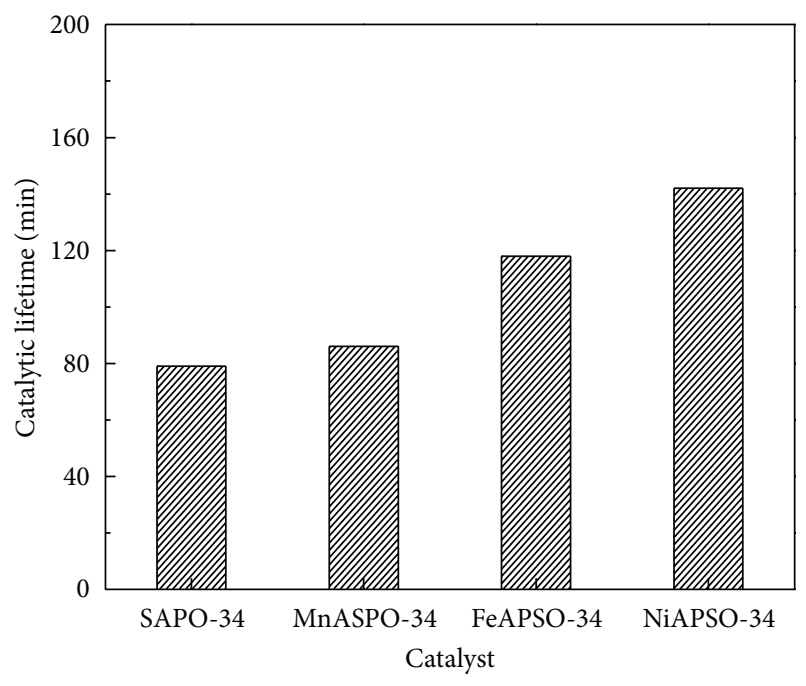

FIGURE 9: Catalytic lifetime of the SAPO-34 and MeAPSO-34 catalysts (catalytic lifetime: the reaction time until the DME conversion drops below 90\%).

selectivities toward light olefins compared with the SAPO-34 catalyst. Among the MeAPSO-34 catalysts, the NiAPSO-34 catalyst demonstrated the longest catalytic lifetime. This result may be explained by the acidity difference between the SAPO-34 catalyst and the MeAPSO-34 catalysts, as observed in the $\mathrm{NH}_{3}$-TPD results. As described above, the difference in the weak acidic sites between the SAPO-34 catalyst and the MeAPSO-34 catalysts is larger than the difference in strong acidic sites. Although the strong acidic sites improve the reactivity, an excess of strong acidic sites induces deactivation due to coke deposition. However, the weak acidic sites are active sites but also delay the coke deposition because they induce mild reaction condition. Therefore, the higher increase in weak acidity resulted in the improvement of catalytic lifetime in the reaction. Consequently, we concluded that metal incorporation is effective in delaying the deactivation of the catalyst during DTO reaction.

\section{Conclusions}

The physical properties of MeAPSO-34 catalysts, including the relative crystallinity and surface area, were similar regardless of the incorporated metal ( $\mathrm{Mn}, \mathrm{Fe}$, or $\mathrm{Ni}$ ). Specifically, metal incorporation improved the crystallinity of catalyst but barely affected the cubic morphology. The MeAPSO-34 catalysts have a relatively high acidity, and the acidity decreased in the order of NiAPSO-34, FeAPSO-34, and MnAPSO-34 catalyst. The catalytic performance of the SAPO-34 and MeAPSO-34 catalysts in the DTO reaction was experimentally investigated. The DME conversion over all of the catalysts decreased during the reaction, and this result is attributed to the conversion of intermediates, such as PAH, formed in the catalytic pores. The selectivity for the light olefins decreased and that for the hydrocarbons increased with increasing time on stream due to the deactivation by coke deposition. The time needed to maintain the total 
selectivity above $95 \%$ for light olefins of the SAPO-34, MnAPSO-34, FeAPSO-34 and NiAPSO-34 catalysts is 185, 208, 254, and $254 \mathrm{~min}$, respectively. The difference in weak acidic sites between the SAPO-34 catalyst and MeAPSO-34 catalysts is higher than the difference in strong acidic sites, and therefore the catalytic lifetime of MeAPSO-34 catalysts is higher than that of SAPO- 34 catalyst. The catalytic lifetimes of the SAPO-34, MnAPSO-34, FeAPSO-34, and NiAPSO-34 catalysts were $79,86,118$, and $142 \mathrm{~min}$, respectively. It was found that the high increase in weak acidity improves the catalytic lifetimes of the MeAPSO-34 catalysts. Therefore, we concluded that the incorporation of transition metal is effective in improving the catalytic lifetime during the DTO reaction.

\section{Conflict of Interests}

The authors declare that there is no conflict of interests regarding the publication of this paper.

\section{Acknowledgment}

This work was supported by the research fund of the Chungnam National University.

\section{References}

[1] S. T. Wilson, B. M. Lok, C. A. Messina, T. R. Cannan, and E. M. Flanigen, "Aluminophosphate molecular sieves: a new class of microporous crystalline inorganic solids," Journal of the American Chemical Society, vol. 104, no. 4, pp. 1146-1147, 1982.

[2] S. Wilson and P. Barger, "The characteristics of SAPO-34 which influence the conversion of methanol to light olefins," Microporous and Mesoporous Materials, vol. 29, no. 1-2, pp. 117126, 1999.

[3] S. Hotevar and J. Levec, "Acidity and catalytic activity of McAPSO-34 ( $\mathrm{Me}=\mathrm{Co}, \mathrm{Mn}, \mathrm{Cr})$, SAPO-34, and H-ZSM-5 molecular sieves in methanol dehydration," Journal of Catalysis, vol. 135, no. 2, pp. 518-532, 1992.

[4] D. B. Akolekar, "Acidity and catalytic properties of AIPO4-11, SAPO-11, MAPO-11, NiAPO-11, MnAPO-11 and MnAPSO-11 molecular sieves," Journal of Molecular Catalysis A, vol. 104, no. 1, pp. 95-102, 1995.

[5] J. W. Park and G. Seo, "IR study on methanol-to-olefin reaction over zeolites with different pore structures and acidities," Applied Catalysis A, vol. 356, no. 2, pp. 180-188, 2009.

[6] G. Sastre, D. W. Lewis, and C. R. A. Catlow, "Modeling of silicon substitution in SAPO-5 and SAPO-34 molecular sieves," Journal of Physical Chemistry B, vol. 101, no. 27, pp. 5249-5262, 1997.

[7] S. Coluccia, L. Marchese, and G. Martra, "Characterisation of microporous and mesoporous materials by the adsorption of molecular probes: FTIR and UV-Vis studies," Microporous and Mesoporous Materials, vol. 30, no. 1, pp. 43-56, 1999.

[8] B. M. Lok, C. A. Messina, R. L. Patton, R. T. Gajek, T. R. Cannan, and E. M. Flanigen, "Silicoaluminophosphate molecular sieves: another new class of microporous crystalline inorganic solids," Journal of the American Chemical Society, vol. 106, no. 20, pp. 6092-6093, 1984.

[9] M. J. van Niekerk, J. C. Q. Fletcher, and C. T. O'Connor, "Effect of catalyst modification on the conversion of methanol to light olefins over SAPO-34," Applied Catalysis A, vol. 138, no. 1, pp. 135-145, 1996.

[10] D. Chen, H. P. Rebo, A. Grønvold, K. Moljord, and A. Holmen, "Methanol conversion to light olefins over SAPO-34: kinetic modeling of coke formation," Microporous and Mesoporous Materials, vol. 35-36, pp. 121-135, 2000.

[11] X. Wu and R. G. Anthony, "Effect of feed composition on methanol conversion to light olefins over SAPO-34," Applied Catalysis A, vol. 218, no. 1-2, pp. 241-250, 2001.

[12] G. Seo and B. G. Min, "Mechanism of methanol conversion over zeolite and molecular sieve catalysts," Korean Chemical Engineering Research, vol. 44, no. 4, pp. 329-339, 2006.

[13] G. Liu, P. Tian, J. Li, D. Zhang, F. Zhou, and Z. Liu, "Synthesis, characterization and catalytic properties of SAPO-34 synthesized using diethylamine as a template," Microporous and Mesoporous Materials, vol. 111, no. 1-3, pp. 143-149, 2008.

[14] K. Y. Lee, H.-J. Chae, S.-Y. Jeong, and G. Seo, "Effect of crystallite size of SAPO-34 catalysts on their induction period and deactivation in methanol-to-olefin reactions," Applied Catalysis A, vol. 369, no. 1-2, pp. 60-66, 2009.

[15] H.-J. Chae, Y.-H. Song, K.-E. Jeong, C.-U. Kim, and S.-Y. Jeong, "Physicochemical characteristics of ZSM-5/SAPO-34 composite catalyst for MTO reaction," Journal of Physics and Chemistry of Solids, vol. 71, no. 4, pp. 600-603, 2010.

[16] Y.-K. Park, K.-C. Park, and S.-K. Ihm, "Hydrocarbon synthesis through $\mathrm{CO}_{2}$ hydrogenation over $\mathrm{CuZnOZrO}_{2}$ /zeolite hybrid catalysts," Catalysis Today, vol. 44, no. 1-4, pp. 165-173, 1998.

[17] P. Wang, A. Lv, J. Hu, J. Xu, and G. Lu, "The synthesis of SAPO-34 with mixed template and its catalytic performance for methanol to olefins reaction," Microporous and Mesoporous Materials, vol. 152, pp. 178-184, 2012.

[18] T. Álvaro-Muñoz, C. Márquez-Álvarez, and E. Sastre, "Use of different templates on SAPO- synthesis: effect on the acidity and catalytic activity in the MTO reaction," Catalysis Today, vol. 179, no. 1, pp. 27-34, 2012.

[19] S.-M. Kim, Y.-J. Lee, J. W. Bae, H. S. Potdar, and K.-W. Jun, "Synthesis and characterization of a highly active alumina catalyst for methanol dehydration to dimethyl ether," Applied Catalysis A, vol. 348, no. 1, pp. 113-120, 2008.

[20] M. Kim, H.-J. Chae, T.-W. Kim, K.-E. Jeong, C.-U. Kim, and S.-Y. Jeong, "Attrition resistance and catalytic performance of spraydried SAPO-34 catalyst for MTO process: effect of catalyst phase and acidic solution," Journal of Industrial and Engineering Chemistry, vol. 17, no. 3, pp. 621-627, 2011.

[21] S. G. Lee, B. K. Yoo, H. S. Je, T. G. Ryu, C. S. Park, and Y. H. Kim, "The study on DME, (dimethyl ether) conversion over the supported SAPO-34 catalyst," Transactions of the Korean Hydrogen and New Energy Society, vol. 22, no. 2, pp. 232-239, 2011.

[22] S. G. Lee, H. S. Kim, Y. H. Kim, E. J. Kang, D. H. Lee, and C. S. Park, "Dimethyl ether conversion to light olefins over the SAPO-34/ZrO ${ }_{2}$ composite catalysts with high lifetime," Journal of Industrial and Engineerinng Chemistry, 2013.

[23] B. M. Weckhuysen, R. R. Rao, J. A. Martens, and R. A. Schoonheydt, "Transition metal ions in microporous crystalline aluminophosphates: isomorphous substitution," European Journal of Inorganic Chemistry, vol. 1999, no. 4, pp. 565-577, 1999.

[24] M. Kang, "Synthesis and catalytic performance on methanol conversion of NiAPSO-34 crystals (II): catalytic performance under various reaction conditions," Journal of Molecular Catalysis A, vol. 150, no. 1-2, pp. 205-212, 1999. 
[25] M. Karthik, A. Vinu, A. K. Tripathi, N. M. Gupta, M. Palanichamy, and V. Murugesan, "Synthesis, characterization and catalytic performance of $\mathrm{Mg}$ and Co substituted mesoporous aluminophosphates," Microporous and Mesoporous Materials, vol. 70, no. 1-3, pp. 15-25, 2004.

[26] Y. Wei, Y. He, D. Zhang et al., "Study of Mn incorporation into SAPO framework: synthesis, characterization and catalysis in chloromethane conversion to light olefins," Microporous and Mesoporous Materials, vol. 90, no. 1-3, pp. 188-197, 2006.

[27] D. Zhang, Y. Wei, L. Xu et al., "MgAPSO-34 molecular sieves with various $\mathrm{Mg}$ stoichiometries: synthesis, characterization and catalytic behavior in the direct transformation of chloromethane into light olefins," Microporous and Mesoporous Materials, vol. 116, no. 1-3, pp. 684-692, 2008.

[28] F. C. Sena, B. F. de Souza, N. C. de Almeida, J. S. Cardoso, and L. D. Fernandes, "Influence of framework composition over SAPO-34 and MeAPSO-34 acidity," Applied Catalysis A, vol. 406, no. 1-2, pp. 59-62, 2011.

[29] S. Ashtekar, A. M. Prakash, D. K. Chakrabarty, and S. V. V. Chilukuri, "Small-pore aluminium phosphate molecular sieves with chabazite structure: incorporation of magnesium in structures-34 and -44," Journal of the Chemical Society, Faraday Transactions, vol. 92, no. 13, pp. 2481-2486, 1996.

[30] D. R. Dubois, D. L. Obrzut, J. Liu et al., "Conversion of methanol to olefins over cobalt-, manganese- and nickel-incorporated SAPO-34 molecular sieves," Fuel Processing Technology, vol. 83, no. 1-3, pp. 203-218, 2003.

[31] M. Salmasi, S. Fatemi, and A. T. Najafabadi, "Improvement of light olefins selectivity and catalyst lifetime in MTO reaction; using $\mathrm{Ni}$ and Mg-modified SAPO-34 synthesized by combination of two templates," Journal of Industrial and Engineering Chemistry, vol. 17, no. 4, pp. 755-761, 2011.

[32] Y. Wei, D. Zhang, L. Xu et al., "Synthesis, characterization and catalytic performance of metal-incorporated SAPO-34 for chloromethane transformation to light olefins," Catalysis Today, vol. 131, no. 1-4, pp. 262-269, 2008.

[33] Y.-H. Song, H.-J. Chae, K.-E. Jeong, C.-U. Kim, C.-H. Shin, and S.-Y. Jeong, "The effect of crystal size of SAPO-34 synthesized using various structure directing agents for MTO reaction," Journal of the Korean Industrial and Engineering Chemistry, vol. 19, no. 5, pp. 559-567, 2008.

[34] M. M. J. Treacy, J. B. Higgins, and R. Ballmoos, Collection of Simulated XRD Powder Patterns for Zeolites, Elsevier, New York, NY, USA, 1996.

[35] A. M. Prakash and S. Unnikrishnan, "Synthesis of SAPO-34: high silicon incorporation in the presence of morpholine as template," Journal of the Chemical Society, Faraday Transactions, vol. 90, no. 15, pp. 2291-2296, 1994.

[36] S. Ashtekar, S. V. V. Chilukuri, and D. K. Chakrabarty, "Smallpore molecular sieves SAPO-34 and SAPO-44 with chabazite structure: a study of silicon incorporation," Journal of Physical Chemistry, vol. 98, no. 18, pp. 4878-4883, 1994.

[37] Y. K. Park, S. W. Baek, and S. K. Ihm, "Effect of reaction conditions and catalytic properties on methanol conversion over SAPO-34," Journal of Industrial and Engineering Chemistry, vol. 7, no. 3, pp. 167-172, 2001.

[38] J. F. Haw and D. M. Marcus, "Well-defined (supra)molecular structures in zeolite methanol-to-olefin catalysis," Topics in Catalysis, vol. 34, no. 1-4, pp. 41-48, 2005. 

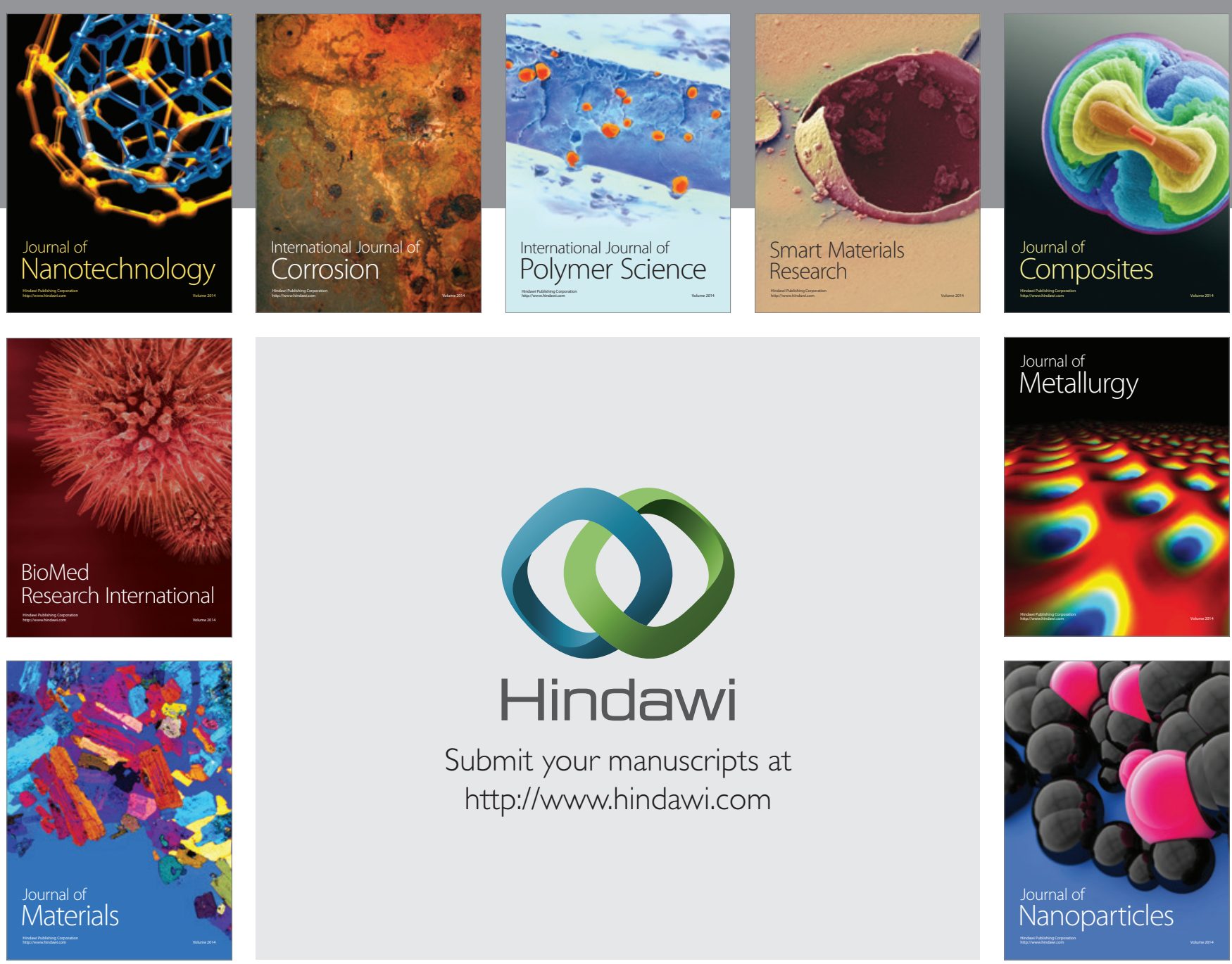

Submit your manuscripts at http://www.hindawi.com
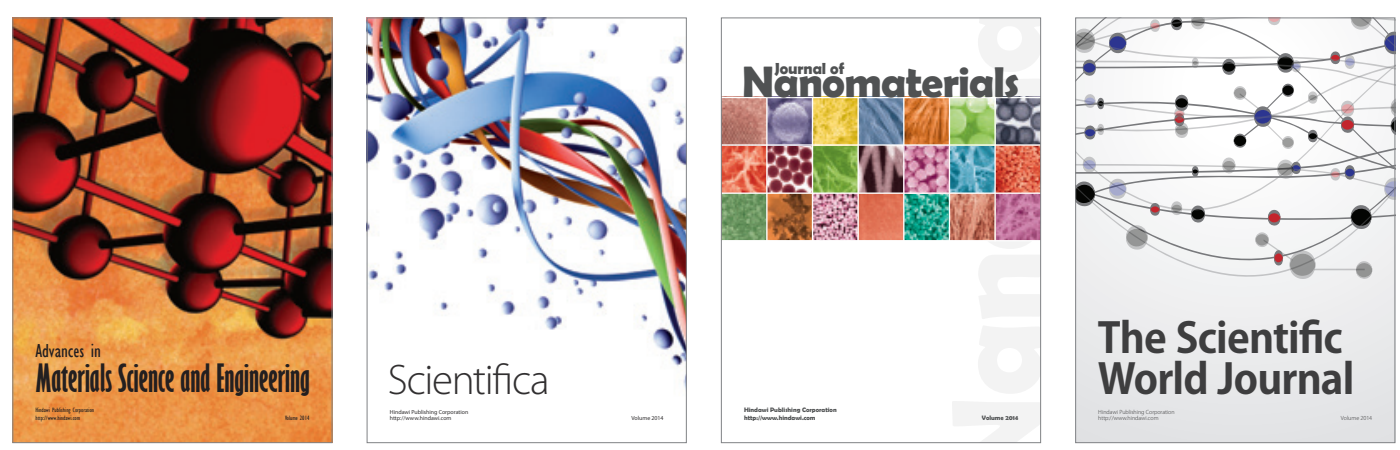

\section{The Scientific World Journal}
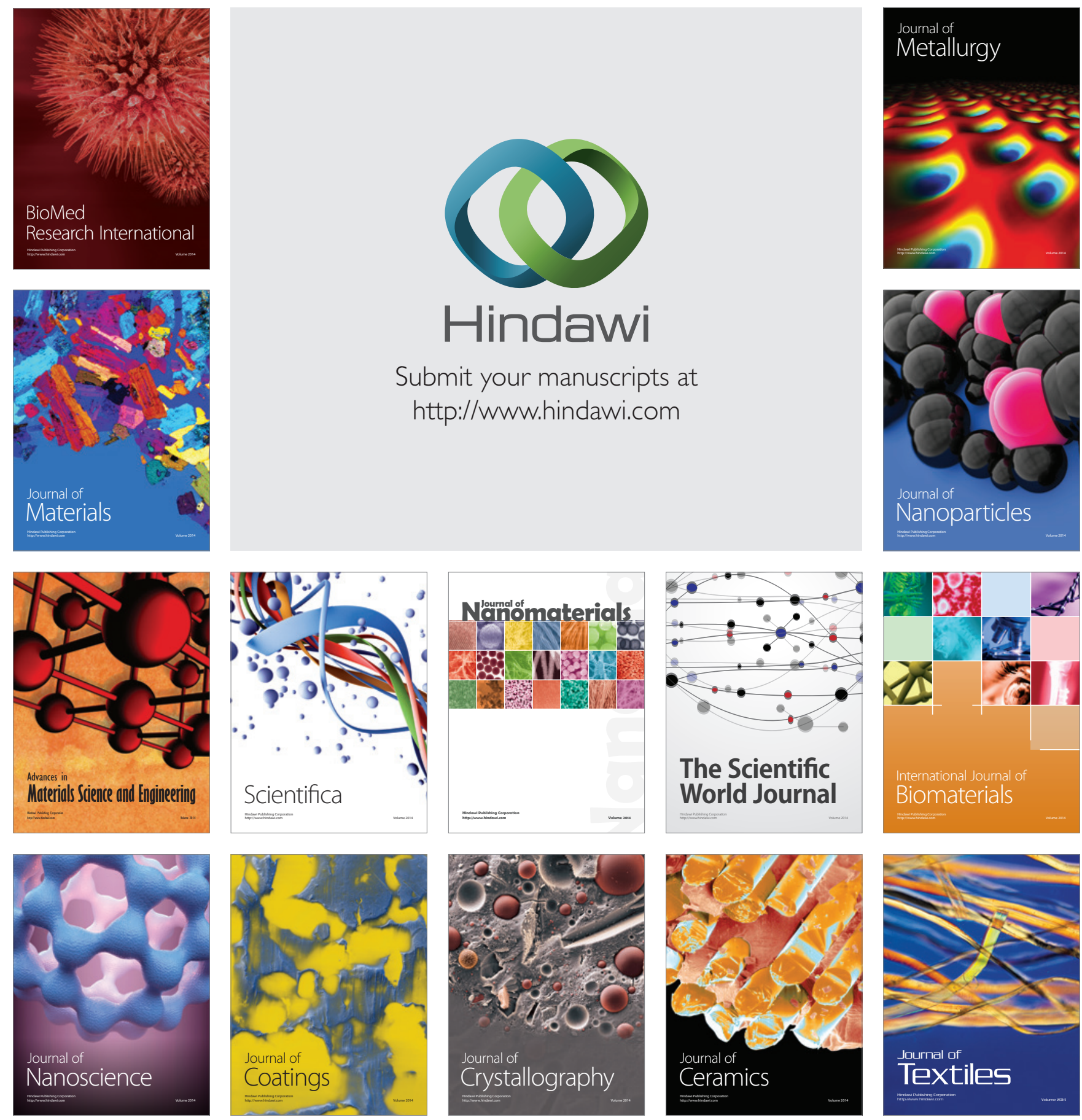